This essay is part of IJARBM's special issue

"Contemporary Applied Business Research

in Light of Standard Academic Literature".

\title{
Knowledge Management and Cultural Diversity: Important Elements in Understanding Conflict
}

\author{
Phyllis Dirrler \\ phyllis.dirrler@yahoo.com \\ MATE Hungarian University of Agriculture and Life Sciences - Kaposvár \\ Campus, Kaposvár, Hungary \\ https://doi.org/10.51137/ijarbm.2022.3.1.9
}

\begin{abstract}
Knowledge sharing is identified as a potential root cause for conflict, whereas knowledge management systems can deal as mediating factors to reduce the costs of conflict. Furthermore, it is evaluated that knowledge sharing and management gains in complexity in case of international cooperation and can be an explaining factor for more conflicts in these work environments. Overall, this essay strengthens the need for knowledge management systems covering cultural aspects.
\end{abstract} Costs

Keywords - Knowledge Management, Cultural Diversity, Conflict

\section{Conflict and Its Costs}

Considering human interactions, conflict is inevitable (Wang et al. 2007) and a permanent companion in our daily lives and the workplace (Buss 2011; Canary et al. 2001). Despite the lack of a holistically accepted definition, conflict can be described as "perceived incompatibilities or discrepant views among the parties involved" (Jehn and Bendersky 2003). Academia presents a wide variety of conflict consequences, reaching from negative effects on team performance or functioning (Jehn and Bendersky 2003; Wit et al. 2012; De Dreu and Weingart 2003) to reduced satisfaction, cooperation, commitment and communication (Jehn and Bendersky 2003). Extending these rather qualitative effects of conflict, conflict can also be investigated quantitively in form of the additional costs it provokes. Conflict costs are the financial costs caused by conflict that negatively affect the overall financial performance of an organization. A company can either achieve its desired outcomes, but with reduced revenue due to the additional financial costs of conflict, or it achieves lower outcomes itself due to the extra costs (Audi et al. 2009). Within my research, four conflict cost clusters were identified, starting with internal direct costs, representing direct effects on a companies' business revenue or desired outcome and correlated to internal stakeholders. These costs can amongst others be legal disputes, theft and damage, as well as an inability to meet deadlines or general productivity 
losses. Followed by internal indirect costs, which solely indirectly affect a companies' business revenue or desired outcome and are also correlated to internal stakeholders. These costs can for example be wasted time worrying about a conflict, avoiding behavior towards the conflict parties, decreased time at work or even psychological and physical diseases. External direct and external indirect conflict costs can be described identically, but apply to external stakeholders, such as customers. These costs can again be legal disputes, but with customers or customer complaint handling or also in case of indirect costs a damage to a company's brand image. Some researchers claim conflict costs to be the highest reducible costs companies currently have (Buss 2011) and emphasize the need for action. To reduce these costs, it is important to understand the different causes of conflict, as well as mediating factors, which have the potential to lower or eliminate certain costs. In this essay one conflict cause and mediating factor is analyzed, which is knowledge sharing and an effective knowledge management within firms. The correlation between conflict and knowledge sharing and management is first described theoretically and then analyzed in terms of international cooperation.

\section{Importance of Knowledge Sharing \& Knowledge Management}

Martinsons and his colleagues (2017) describe knowledge as an important resource for organizations, which is essential for its success, employee productivity and a competitive advantage. Each employee within a company possess knowledge, based on his or her experiences, education or expertise made in life. Consequently, differences in knowledge and skills are present in any firm worldwide, which can also be labeled as information or functional diversity (Stasser 1992; Jehn et al. 1999). This diversity increases task conflict, which describes conflict situations involving divergent opinions or ideas about a task and process conflict, which refers to arguments over logistical topics, such as resource allocation or task assignments (Jehn 1995; Jehn 1997; Jehn et al. 1999). These conflictual situations based on diversity, can also be linked to different conflict costs; firstly, to internal direct conflict costs in form of performance declines, decreased quality at work and productivity losses. In addition, it can hinder work groups to meet deadlines or can lead to bad decision making. These costs can be caused by different reasons, such as people not wanting to share their knowledge in order to remain superior, the fear of people to ask for help, especially out-group members or the intention by a person or group to spread wrong or missing information to harm others. In extreme situations, internal indirect costs can evoke as well, in case of group members worrying about the caused conflict or knowledge gap, potentially even leading to other costs such as extra time gathering information or psychological diseases. External indirect costs can in addition be caused in case of companies implementing knowledge management solutions just for marketing reasons, instead of real interest in the systems themselves. In case of the exposure of the real causes, it might 
harm the company's reputation or brand image. An example for this risk was also presented by Martinsons et al. (2017) where the investigated company was more interested in gaining a modern business image for marketing purposes instead of actually saving transaction costs. Even though information or functional diversity is naturally present, it needs to be managed in order to benefit from knowledge diversity, while keeping the negative effects of it, like conflict, low. Knowledge management systems can be an effective tool to benefit from information or functional diversity, while keeping the potential risks of conflict low and are increasingly researched, such as in the article of Martinsons and colleagues (2017). Knowledge management deals with the capture, retention, processing, and reuse of knowledge and enables collaboration across borders and despite different time zones.

\section{Difficulties of Knowledge Management}

Due to the benefits of knowledge management systems for organizations, there is an increasing interest for its implementation and management within the academic and business world. Academia presents an increasing number of literature on the topic, mostly about successful knowledge management implementations in Western firms, but miss out to analyze the reasons for failure. However, knowledge management systems often cannot meet deadlines, budgets or performance expectations and seem to be less successful in China compared to other, mainly Western countries (Martinsons et al. 2017). Martinsons et al. (2017) investigate knowledge management systems in two Chinese small professional firms and conclude that Western theories within this research field, cannot just be copied to China, because cultural and institutional differences matter. They further highlight that there is no universal system because success and failures aren't universal either. However, over the last decades a continuous growth of the global economy was taking place, so that geographical borders were overcome by organizations, new markets emerged and the overall workforce became more diverse in terms of nationality (Ascalon et al. 2008), positioning diversity into the center of organizational life (Williams and O'Reilly, III 1998). In the next step, a hypothetical business set-up is created of a Chinese German company and evaluated how different cultures influence knowledge sharing and management. Lastly, it is then evaluated whether knowledge sharing and management, linked with cultural diversity can be used to partly explain why cultural diversity increases conflict, as stated by different researchers (Vodosek 2007; Kankanhalli et al. 2006).

\section{$4 \quad$ Culture Matters}

For China, Martinsons et al. (2017) report that based on the cultural dimensions of Hofstede (2001) China is classified as a high-power distance and collectivism country, signifying that senior management is not expected to ask subordinates for knowledge or opinions and where employees lower in the hierarchy do not openly share their knowledge. In addition, losing, 
maintaining or improving one's "face" is of great importance, meaning that people are more likely to exchange ideas or information if they see a chance of improving their face and are less likely to get involved in any activity which could negatively influence their personal reputation. Successful interaction in China relies on interpersonal relationships and trust, rather than formal systems. This was further strengthened by the research findings of the authors, where the majority of employees preferred fact-to-face interactions and instant messaging tools. Furthermore, most subordinates didn't see considerable value in the implemented knowledge management system, but didn't communicate it openly to preserve the face of the managers. In both firms, decisions about the layout and implementation of systems were made by the senior management solely. These difficulties are already immense in solely national Chinese firms, but increase by adding a German counterpart. China's power distance index is 80 compared to Germany's index of 35. Within the individualism category China ranks very low with an index of 20 , signifying stronger collectivism values, compared to Germany with a relatively high individualism score of 67 . According to the high power distance index, the Chinese work environment is characterized by strong hierarchical structures and centralized decision structures in comparison to decentralized decision structures and flat organizational pyramids with a lower focus on hierarchies. China's workforce, categorized as a collectivism country, is more likely to share information and knowledge openly, but mainly in favor of in-groups. A strong focus lies on personal relationships, representing a family alike relation between employees, whereas people generally act, hire or promote in favor of their close contacts. Germany in comparison ranks high on the individualism index, which means that people are more likely to withhold information, avoid alliances and relationships are purely focused on skills and work relations. Close relationships, such as family bonds, are seen as a disadvantage and communication, hiring or promotions are solely based on skills and rules, regardless of personal preferences. Considering Hofstede's theory and the opposing countries; it can be concluded that general knowledge sharing is difficult between the employees. Chinese employees are expected to be seen as an in-group among themselves, where information is shared openly, often also using informal ways. However, knowledge sharing takes place on the same hierarchical level, always with the intent to maintain or improve one's face. German employees would rather be out-group members, with a geographic and temporal distance and language barriers, where less informal knowledge sharing or communication can take place. As the German culture emphasizes rules and skills above personal relationships, a lower preference towards other German employees can be expected. However, as they generally tend to share less information, knowledge information in this case is difficult as well. Further difficulty is added in case of communication, where Germans would openly challenge and question a manager's decisions and statements and freely share their own ideas and thoughts, Chinese employees wouldn't express any doubts. This example demonstrates the complexity of knowledge sharing in global companies and also emphasizes roughly the difficulties of the implementation and usage of knowledge management systems in this context. It can 
therefore be concluded that cultural diversity, linked to knowledge sharing can be one reason for more conflict in case of international cooperation. To the same time, it highlights the potential of knowledge management system in international working environment as a mediating factor to reduce or eliminate the costs of conflict caused by cultural and information diversity. However, to the same time, the challenges of a successful implementation are presented and need to be considered.

\section{Conclusion for the Scientific and Business World}

Within this essay, knowledge sharing was extracted as a root cause of conflict, whereas knowledge management systems can serve as a mediating factor in case of successful implementation. By correlating these two research fields, a new perspective is presented and explained, using diversity theory. Martinsons et al. (2017) already reported the need for successful knowledge management and understanding their failures. By adding conflict, this need is further emphasized, because a new dimension of costs is presented, which appear in case of mismanagement. However, as Martinsons et al. (2017) only researched two small Chinese national firms and concluded that culture matters in knowledge management, this finding was extended by adding a more globalized view on this topic, based on the theory of Hofstede (2001). Theoretically, it can be concluded that knowledge sharing gets even more difficult in global set-ups, fostering more difficulties and in the end higher conflict costs. Knowledge management systems were identified as moderating factors counteracting many problems, but present new challenges to the same time. Considering conflict costs as the highest reducible costs for today's organizations and the potential of knowledge management systems to reduce these costs, a further need for research can be identified. Both analysis, the research note (Martinsons et al. 2017) and this essay still do not provide profound findings. The limitation mainly lies on the small quantity of investigated firms, as well as only making a theoretical example of a German Chinese company. Future research should focus on global firms, when evaluating knowledge management systems and combine universal approaches with local characteristics. Businesses need to be aware of the costs of ineffective knowledge management, which go beyond the costs of a failed project and can reach high amounts due to transactional costs, as well as conflict costs. Therefore, a stronger urgency is needed by top-management to embed the topic of knowledge management in a strategic vision, to represent it and demand it within the whole organization and to accept higher costs. In the end, the costs of failed knowledge management can surpass the costs of a failed project or expensive IT infrastructure by far and cause conflict, harming the organizational qualitatively and quantitatively. 


\section{References}

Ascalon, Evelina; Schleicher, Deidra J.; Born, Marise (2008): Cross-cultural social intelligence. An assessment for employees working in crossnational contexts. In Cross Cultural Management 15 (2), pp. 109-130.

Audi, Manuel; Bauernfeind, Barbara; Feichtner, Edgar; Kerntke, Wilfried; Seidel, Uwe M.; Renger, Dieter et al. (2009): Konfliktkostenstudie. Die Kosten von Reibungsverlusten in Industrieunternehmen. In KPMG.

Buss, Helmut (2011): Controlling Conflict Costs: The Business Case of Conflict Management. In Journal of the International Ombudsman Association 4 (1).

Canary, Daniel J.; Cupach, William R.; Serpe, Richard T. (2001): A Competence-Based Approach to Examining Interpersonal Conflict: Test of a Longitudinal Model. In Communication Research 28 (1), pp. 79-104.

De Dreu, Carsten K.W.; Weingart, Laurie R. (2003): Task versus Relationship conflict, team performance, and team member satisfaction: a metaanalysis. In Journal of Applied Psychology 88 (4), pp. 741-749.

Hofstede, Geert H. (2001): Culture's consequences. Comparing values, behaviors, institutions, and organizations across nations / Geert Hofstede. 2nd ed. Thousand Oaks, Calif., London: SAGE.

Jehn, K. A.; Northcraft, G. B.; Neale, M. A. (1999): Why differences make a difference: A field study of diversity, conflict, and performance in workgroups. In Administrative Science Quarterly 44 (4), pp. 741-763.

Jehn, Karen (1997): A Qualitative Analysis of Conflict Types and Dimensions in Organizational Groups. In Administrative Science Quarterly 42 (3), pp. $530-557$. 
Jehn, Karen; Bendersky, Corinne (2003): Intragroup conflict in organizations: A contingency perspective on the conflict-outcome relationship. In Research in Organizational Behavior 25, pp. 187-242.

Jehn, Karen A. (1995): A multimethod examination of the benefits and detriments of intragroup conflict. In Administrative Science Quarterly 40 (2), pp. 256-282.

Kankanhalli, Atreyi; Tan, Bernhard C.Y.; Wei, Kwok-Kee (2006): Conflict and Performance in Global Virtual Teams. In Journal of Management and Information Systems 23 (3), pp. 237-274.

Martinsons, Maris G.; Davison, Robert M.; Huang, Qian (2017): Strategic knowledge management failures in small professional service firms in China. In International Journal of Information Management 37, pp. 327338.

Stasser, G. (1992): Information salience and the discovery of hidden profiles by decision-making groups: A 'thought experiment'. In Organizational Behavior and Human Decision Processes 52, pp. 156-181.

Vodosek, Markus (2007): Intragroup conflict as a mediator between cultural diversity and work group outcomes. In International Journal of Conflict Management 18 (4), pp. 345-375.

Wang, Guofeng; Jing, Runtian; Klossek, Andreas (2007): Antecedents and management of conflict. Resolution styles of Chinese top managers in multiple rounds of cognitive and affective conflict. In International Journal of Conflict Management 18 (1), pp. 74-97. 
Williams, Katherine Y.; O'Reilly, Charles A., III (1998): Demography and diversity in organizations: A review of 40 years of research. In Research in Organizational Behavior 20, pp. 77-140.

Wit, Frank R.C. de; Greer, Lindred L.; Jehn, Karen A. (2012): The Paradox of Intragroup Conflict: A Meta-Analysis. In Journal of Applied Psychology 97 (2), pp. 360-390. 